\title{
ORIGINAL ARTICLE Quality of life of former preterm adolescents
}

\author{
Qualidade de vida de adolescentes nascidos prematuros \\ Rozane Lapoli Sanz Casseb?, Ethel Cukierkorn Battikha', Ana Lucia Goulart', Anna Luiza Pires Vieira', \\ Marina Carvalho de Moraes Barros', Amélia Miyashiro Nunes dos Santos'
}

\section{Keywords}

Premature, quality of life, maternal behavior, WHOQOL-BREF.

\section{RESUMO}

Objetivos: Comparar a qualidade de vida de adolescentes nascidos prematuros com muito baixo peso na percepção do adolescente e de seu cuidador e analisar os fatores associados na visão de ambos. Métodos: Estudo transversal com adolescentes nascidos com idade gestacional $<37$ semanas e peso $<1.500 \mathrm{~g}$, em acompanhamento no ambulatório de prematuros de uma instituição universitária, do nascimento à adolescência, e seus cuidadores. Pesquisou-se a qualidade de vida com o questionário WHOQOL-BREF. Fatores associados à qualidade de vida foram analisados por regressão linear. Resultados: Dos 91 adolescentes elegíveis, 73 (80,2\%) foram incluídos, sendo 38 (52,1\%) masculinos, nascidos com 30,1 $\pm 2,4$ semanas de gestação e

1 Federal University of São Paulo, Department of Pediatrics, São Paulo, SP, Brazil.

Received in

$4 / 5 / 2018$

Approved in

$25 / 8 / 2018$

DOI: $10.1590 / 0047-2085000000200$

\begin{abstract}
Objectives: To compare the quality of life of adolescents born prematurely with verylow-birth-weight, reported by adolescents themselves and their caregivers, and analyze associated factors perceived by both. Methods: This cross-sectional study included former preterm adolescents born with gestational age $<37$ weeks and birth weigh $<1,500 \mathrm{~g}$, who were being followed up at the premature outpatient clinic of a university institution, from birth to adolescence, and their caregivers. Quality of life was assessed by the WHOQOLBREF questionnaire. Factors associated with quality of life were analyzed by linear regression. Results: Of 91 eligible adolescents, 73 (80.2\%) were included, being 38 (52.1\%) male. The mean gestational age was $30.1 \pm 2.4$ weeks and birth weight was $1134 \pm 239 \mathrm{~g}$. Adolescents reported better quality of life than their caregivers $(p=0.011)$, being respectively: dissatisfied (1.4 vs. $4.1 \%)$, neither satisfied nor dissatisfied (20.5 vs. 20.5\%), satisfied (56.2 vs. $71.2 \%$ ) and very satisfied (21.9 vs. 4.1\%). Scores attributed by adolescents and caregivers were, respectively: overall quality of life ( $4.0 \pm 0.7$ vs. $3.8 \pm 0.6, p=0.032)$, physical domain ( $3.6 \pm 0.6$ vs. $3.5 \pm 0.6, p=0.685$ ), psychological domain $(3.4 \pm 0.6$ vs. $3.6 \pm 0.6, p=0.116)$, social relationships $(3.7 \pm 0.7$ vs. $3.6 \pm 0.8$, $p=0.371)$ and environment ( $3.4 \pm 0.7$ vs. $3.2 \pm 0.6, p=0.037)$. For caregivers, absence of fixed partner and hospitalization in childhood decreased the overall quality of life score; furthermore, the occurrence of respiratory distress syndrome increased this score. In the adolescents' view, leukomalacia reduced this score. Conclusions: Adolescents reported better quality of life than caregivers. For adolescents, only biological factors were associated with quality of life scores; for caregivers, biological and social factors were associated this scores.
\end{abstract}

\author{
Address to correspondence: Amélia Miyashiro Nunes dos Santos \\ Rua Diogo de Faria, 764 \\ Vila Mariana \\ 04037-002 - São Paulo, SP, Brazil \\ Email:ameliamiyashiro@yahoo.com.br
}




\section{Palavras-chave}

Prematuro, qualidade de vida, comportamento materno, WHOQOL-BREF. peso de $1.134 \pm 239 \mathrm{~g}$. Adolescentes referiram melhor qualidade de vida que seus cuidadores $(p=0,01)$, sendo, respectivamente: insatisfeitos (1,4 vs. 4,1\%), nem satisfeitos, nem insatisfeitos (20,5 vs. 20,5\%), satisfeitos (56,2 vs. 71,2\%) e muito satisfeitos (21,9 vs. 4,1\%). Os escores atribuídos pelos adolescentes e cuidadores foram, respectivamente, qualidade de vida geral $(4,0 \pm 0,7$ vs. 3,8 $\pm 0,6, p=0,032)$, domínio físico $(3,6 \pm 0,6$ vs. 3,5 $\pm 0,6, p=0,685)$, domínio psicológico $(3,4 \pm 0,6$ vs. 3,6 $\pm 0,6, p=0,116)$, relações sociais $(3,7 \pm 0,7$ vs. 3,6 $\pm 0,8, p=0,371)$ e ambiente $(3,4 \pm 0,7$ vs. 3,2 $\pm 0,6, p=0,037)$. Para cuidadores, ausência de parceiro fixo e hospitalização na infância diminuíram os escores de qualidade de vida geral, já a síndrome de desconforto respiratório aumentou esse escore. Na percepção dos adolescentes, a leucomalácia reduziu esse escore. Conclusões: Adolescentes referiram melhor qualidade de vida que seus cuidadores. Para adolescentes, apenas fatores biológicos se associaram aos escores de qualidade de vida; para cuidadores, fatores biológicos e sociais se associaram a esse escore.

\section{INTRODUCTION}

Preterm children and adolescents are at increased risk of developmental delays in addition to psychological, emotional and behavioral disorders that may compromise their quality of life ${ }^{1-4}$. A systematic review showed that preschoolers born preterm or with very low birth weight had lower quality of life scores compared with those born at term in the physical health, psychological and/or social relationships domains. In turn, those born extremely preterm presented lower quality of life scores than those born at term in both school age and adolescence ${ }^{5}$.

Saigal et al. ${ }^{6}$ compared quality of life using the Health Utilities Index (HUI3) in individuals with age ranges of 1216, 22-26 and 29-36 years old, where 37 were extremely preterm with sequelae, 116 were extreme premature with no sensorineural sequelae and 137 were born with normal weight. Adjusted for gender and socioeconomic level, extremely preterm with neurosensory sequelae had lower quality of life scores compared with those extreme premature without sequelae and those who were born with normal weight. Premature without sequelae also had lower scores than those born at term.

The assessment of health-related quality of life in children younger than 5-7 years of age or in individuals with a limitation that makes it difficult to evaluate their own symptoms or feelings is completed through an interview with their most direct caregiver ${ }^{5}$, and it is not uncommon for children to disagree with their parents about their quality of life assessment. Zwicker and Harris ${ }^{5}$ compared the quality of life scores attributed by parents to those attributed by preterm adolescents and reported lower scores among parents in overall, behavioral and physical health domains. In adulthood, the difference between parents and patients persisted only in the physical health domain ${ }^{5}$.

The hypothesis of the present study is that the perception of the quality of life of adolescents born prematurely may not be a faithful picture of their state of health and the degree of sequelae of prematurity due to the subjective and multidimensional character attributed to the perception of quality of life. In addition, it is assumed that the adolescent and his caregiver differently portray the perception of quality of life and that this difference is possibly influenced by diverse biopsychosocial factors.

Considering the lack of studies on quality of life in adolescents born prematurely in our country using a validated instrument in Portuguese and originally developed with people of several nationalities, including Brazilians ${ }^{7}$, we planned this study.

In this context, the objectives of this study were to compare the perception of overall quality of life as reported by the adolescent born prematurely with that reported by his/her caregiver and to analyze the factors that were associated with the quality of life scores in the views of both groups, using the WHOQOL-BREF questionnaire?.

\section{METHODS}

This cross-sectional study was approved by the Research Ethics Committee of the Federal University of São Paulo and was conducted after obtaining a signed Informed Consent Form from the guardian and an Assent Form from the adolescent. The study was carried out from July 2012 to June 2015.

Inclusion criteria were adolescents aged 10-19 years, born with a gestational age $<37$ weeks and birth weight $<1,500 \mathrm{~g}$, born at the Federal University of São Paulo from 1995 to 2003 and were in follow-up at the Outpatient Clinic for Prematures of the institution, and their caregivers. In this outpatient clinic, preterm infants born at the institution were followed-up from birth to adolescence by a multidisciplinary team composed by pediatricians, pediatric neurologists, physiotherapists, 
speech therapists, psychologists, occupational therapists, ophthalmologists, dermatologists, dentists, nutritionists and social workers. The caregiver included in the study was the one who had greater daily contact with the adolescent.

Adolescents who died before the study or were unable to respond to the questionnaire due to clinical or neurological limitations or who did not have a caregiver with a wellestablished affective bond that could provide information about the child's quality of life were excluded.

The WHOQOL-BREF questionnaire developed by the World Health Organization and translated and validated into Portuguese by Fleck et al. ${ }^{7}$ was applied to adolescents and their respective caregivers. This instrument consists of 26 questions divided into two specific questions on overall quality of life and 24 questions subdivided into four domains: physical health, psychological, social relationships and the environment.

The same researcher applied the questionnaire, randomly to the adolescent and to his/her caregiver, on the same day, and separately, without the knowledge of each other's answers. In the interview, the researcher read the questions of the questionnaire for the interviewees. The questionnaire was answered based on the last two weeks.

The demographic, clinical and socioeconomic data of mothers and adolescents, relative to perinatal and neonatal period were collected from the medical records of the neonatal unit. Data related to the follow-up period at the out clinic were collected by chart review and additional information asked to the mother or the caregiver.

The analysis of quality of life scores was performed according to the domain, assigning a score from 1 to 5 for each question. In each domain, the total number of points was divided by the number of questions to always maintain a result with a score from 1 to 5 .

Negative questions were reversed so that higher intensity scores represented a higher quality of life.

\section{Statistical analysis}

Numerical variables with normal distribution were expressed as means and standard deviations and were compared by t-test. Categorical variables were expressed as single frequencies and compared by the Chi-square or Fisher's exact test. To analyze the internal validity of the questionnaire, the Cronbach coefficient was used ${ }^{8}$. Linear regression was used to analyze the factors associated with the quality of life score. Variables of clinical interest were included in the univariate model. In the multiple linear regression, the variables with statistical significance of $p<0.2$, as identified in the univariate model, were included. Finally, in the multiple model, only variables with $p$ value $<0.05$ were considered. The analyses were performed with SPSS for Win/V.17.0 (IBM SPSS Statistics, Somers, NY, USA), and the level of statistical significance was set at $\mathrm{p}<0.05$ for all analysis.

\section{RESULTS}

A total of 73 (80.2\%) preterm adolescents with very low birth weight who fulfilled the inclusion criteria were included. The flowchart of patients eligible for the study is shown in Figure 1.

The mean age of the adolescents' mothers at the time of inclusion in the study was $44.1 \pm 7.5$ years, and 27 (37.0\%) mothers had no fixed partner. The mean years of schooling of the caregiver was $8.0 \pm 3.9$, and the median monthly family income was BRL 1,800.00 (variation: BRL 600.00 to 8,000.00).

Maternal data related to gestational period were shown in Figure 2.

Regarding breastfeeding, 34 (46.6\%) mothers breastfed their child, and no preterm infant received exclusive breastfeeding. Among those who breastfed, 10 (29.1\%) mothers breastfed for 1 month, and only 2 (5.9\%) mothers breastfed for six months.

Of the adolescents included, 38 (52.1\%) were male, the mean gestational age was $30.1 \pm 2.4$ weeks (range: $26-36$ weeks), their weight was $1134 \pm 239 \mathrm{~g}$ (range: 560 to $1495 \mathrm{~g}$ ), and their 5 -minute Apgar was $8 \pm 2$ minutes. In the neonatal unit, $58.3 \%$ of neonates required mechanical ventilation and the median length of hospital stay was 50.5 days (13 to 338 days), and the frequency of neonatal morbidity were shown in Figure 3.

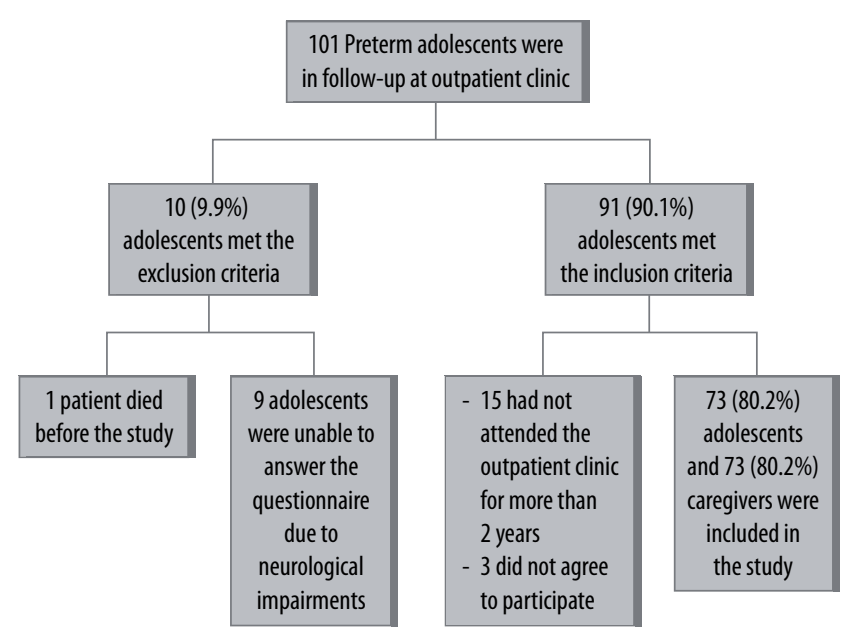

Figure 1. Patient's flowchart of the study.

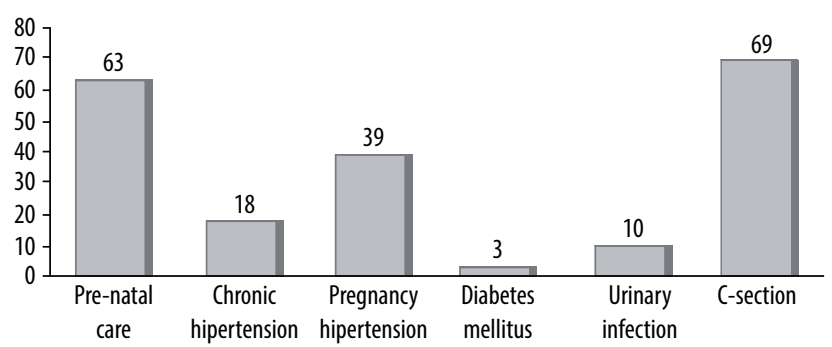

Figure 2. Maternal clinical and gestacional intercorrences during gestation and mode of delivery (in percentage of mothers). 
After discharge from the neonatal unit, until inclusion in the study, 38 (52.1\%) adolescents had been hospitalized at least once (range: 1 to 40), with respiratory causes or correction of inguinal hernia predominating.

According to the evaluation of the multidisciplinary team that provides assistance to the adolescents included in the study, almost half of them presented any adverse outcome (Figure 4). In consequence, 55.7\% of adolescents needed some support, such as glasses (31.5\%), orthodontic braces (26.0\%) or wheelchairs (2.7\%), and $12.3 \%$ depended on someone to tie their shoes, care for personal hygiene, change their clothes or help with feeding.

Of 73 adolescents, none reported tobacco, alcohol or drug use, 3 (4.1\%) had started sexual activity, and 13 (17.8\%) practiced any type of physical activity for at least 30 minutes, three times a week.

At the time of inclusion in the study, the mean age of the adolescents was $13.4 \pm 2.7$ years. They were living with more than one relative, except for 2 (2.7\%) who were living only with their mother; 49 (67.1\%) were living with their father and mother, with or without other family members, 15 with their mother and another relative or stepfather and 7 (9.6\%) with relatives.

Regarding schooling, 40 (55.5\%) had studied less than 9 years, and 5 (6.8\%) adolescents had repeated at least one grade at school.

The caregivers who answered the questionnaire were as follows: 62 (84.9\%) mothers, 2 (2.7\%) fathers, 3 (4.1\%)

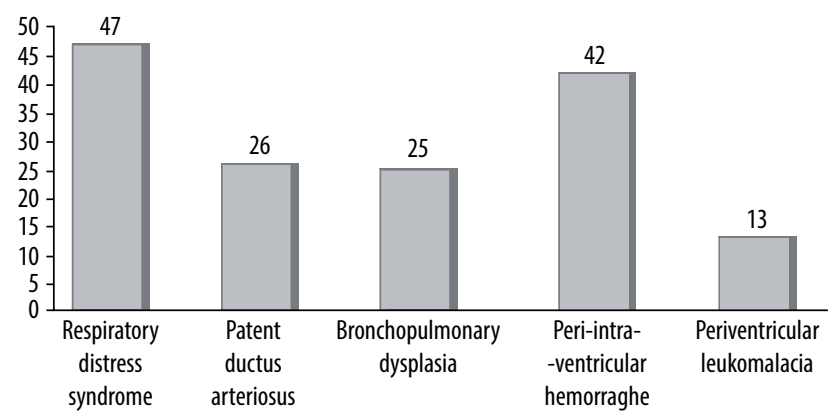

Figure 3. Percentages of neonates with clinical intercorrence during hospitalization in the neonatal unit.

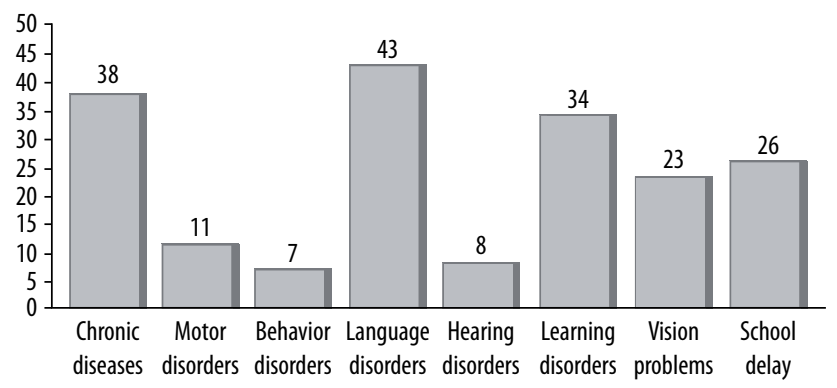

Figure 4. Percentages of adolescents with any impaired outcome at study entry. maternal grandmothers, 1 (1.4\%) paternal grandmother, 1 (1.4\%) maternal aunt, 1 (1.4\%) paternal aunt and 3 (4.1\%) sisters. The mean time of completion of the questionnaire by the adolescents was $7.8 \pm 2.4$ minutes, and the mean time of completion by the caregivers was $9.4 \pm 3.1$ minutes ( $p=$ 0.001).

The internal validity values of the questionnaire assessed by the Cronbach coefficient were 0.84 for the questionnaire answered by the adolescents and 0.93 for the questionnaire answered by the caregiver.

There were statistically significant differences in the overall quality of life and environment domain scores attributed by the adolescent and his/her caregiver, respectively. In the other domains, both attributed similar scores (Table 1). However, in the psychological domain, specifically concerning a question related to the frequency of experiencing negative feelings, the adolescents reported a higher frequency of these feelings than those perceived by the caregivers $(p<0.001)$.

Regarding overall quality of life, there was a difference in the opinions of the interviewees, with a higher percentage of adolescents reporting being very satisfied with their quality of life compared with their caregivers ( $22 \%$ vs. $4 \%, p=0.011$ ) (Figure 5).

Table 1. Scores attributed by adolescentes and their caregivers for each domain of the WHOQUOL-BREF questionnaire

\begin{tabular}{lccc}
\hline Domains & $\begin{array}{c}\text { Adolescents } \\
(\mathrm{n}=73)\end{array}$ & $\begin{array}{c}\text { Caregivers } \\
(\mathrm{n}=73)\end{array}$ & $\mathbf{p}$ \\
\hline Overal quality of life & $4.0 \pm 0.7$ & $3.8 \pm 0.6$ & 0.032 \\
Physical health & $3.6 \pm 0.6$ & $3.5 \pm 0.6$ & 0.685 \\
Psychological & $3.4 \pm 0.6$ & $3.6 \pm 0.6$ & 0.116 \\
Social relationships & $3.7 \pm 0.7$ & $3.6 \pm 0.8$ & 0.371 \\
Environment & $3.4 \pm 0.6$ & $3.2 \pm 0.6$ & 0.037 \\
\hline
\end{tabular}

p-value: t test. Scores ranged from 1 to 5 for each domain.

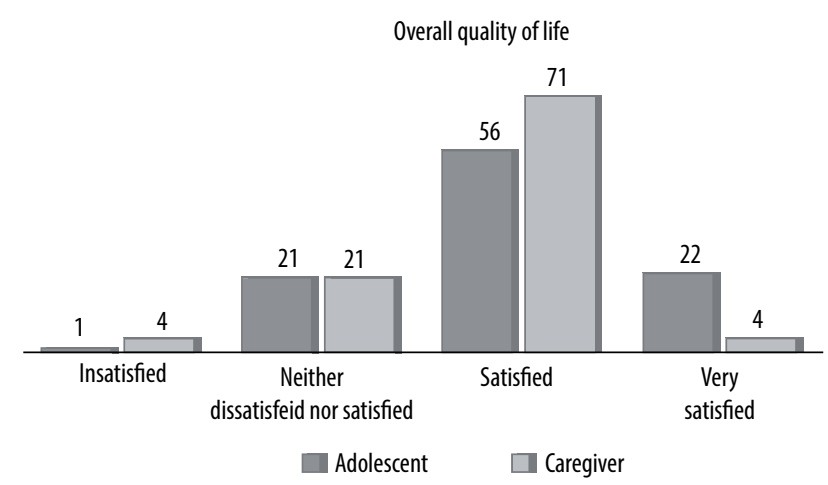

Figure 5. Percentages of adolescents and their caregivers according to their opinion on the adolescents' overall quality of life ( $\chi^{2}$ test, $\left.p=0.011\right)$. 
The analysis of the factors associated with overall quality of life score, by multiple linear regression, controlled for the following variables - no fixed partner, smoking during gestation, diabetes mellitus, respiratory distress syndrome, leukomalacia and number of hospitalizations showed that, in the caregivers' perception:

- The mother not having a fixed partner reduced the quality of life score by 0.253 points (95\% confidence interval [95\% Cl] -0.494 to $-0.013, \mathrm{p}=0.039$ ).

- Adolescent patients having respiratory distress syndrome in the neonatal period increased the quality of life score by 0.420 points ( $95 \%$ Cl: 0.184 to $0.656, p$ $=0.001)$.

- Each hospital admission during childhood decreased the quality of life score by 0.031 points (95\% Cl: -0.053 to $-0.009 ; p=0.007$ ).

In regard to the factors related to the adolescents, controlled for the variables gender, age, peri-intraventricular hemorrhage, leukomalacia and visual disturbance, found in the univariate linear regression, only the periventricular leukomalacia persisted in the final model, decreasing the overall quality of life score by 0.661 points $(95 \% \mathrm{Cl}$ : -1.103 to $-0.132, p=0.015)$.

\section{DISCUSSION}

The present study showed that very low birth weight preterm infants presented high frequencies of neonatal morbidity and sequelae in infancy and adolescence due to prematurity. However, the mean score of quality of life of adolescents was satisfactory in both perception of the adolescent himself/ herself and his/her caregiver. In addition, more than three-quarters of the adolescents studied reported being satisfied or very satisfied with their quality of life. Some studies comparing the quality of life reported by adolescents born prematurely and those born at term showed similar levels of quality of life ${ }^{9-11}$. It is possible that adolescents who were born preterm find satisfaction in overcoming the challenges that the sequelae from prematurity impose on them. This fact proves to be challenging for the team involved in the care of extremely preterm neonates, especially those within the limits of viability, particularly when having to counter the neurological prognosis with the paradox of the incapacity, in which the individual, despite his unfavorable health condition, perceives his life as being good ${ }^{12}$.

Compared with adolescents, caregivers attributed lower quality of life and environmental scores. The disagreement between adolescents and caregivers regarding the perception of quality of life has already been reported in other studies $5,13,14$. These results show the adolescents' independence in reporting their quality of life, differing significantly from that of their caregivers, suggesting that the adolescent speaks for himself/herself and that their report plays an important role in the overall evaluation of his/her condition. The independence of opinion between the adolescents and their caregiver may demonstrate its importance in showing that despite the prematurity and with the excessive dependence on their caregiver in the first stages of life, the adolescent studied here was a distinct subject, having acquired his identity. Still, these results may express the difficulties in mother-adolescent relationship, as preterm birth may represent a traumatic experience for the mother and thus negatively influence the maternal perception of her child throughout life ${ }^{15}$. In this sense, a new study design is need for evaluate this question.

In the Physical Health and Social Relationships domains, the scores attributed by the adolescent were similar to those of the caregiver, suggesting a tuning among peers, especially in the domains characterized by more objective and concrete aspects ${ }^{16,17}$.

In the Psychological domain, although the overall score was similar among adolescents and caregivers, in a specific question related to the frequency of negative feelings, the responses of the adolescents had significant greater occurrence compared with those of the caregivers. Some authors believe that the evaluation of the individual is closer to reality in regard to feelings and symptoms of internalization, such as sadness, pain and fatigue, while the parents' opinion is more relevant regarding symptoms of externalization, such as hyperactivity and aggressiveness ${ }^{16,17}$.

The discrepancies between patient and caregiver information point to the need to identify the variables that contribute to such differences. In this sense, in the caregiver's perception, the adolescent's quality of life score increased if the child had developed respiratory distress syndrome in the neonatal period and decreased when the number of hospitalizations increased during childhood and adolescence and when the caregiver did not have a fixed partner. In the adolescents' own perception, their quality of life significantly decreased in the presence of periventricular leukomalacia, revealing a relationship between neurological impairment and quality of life ${ }^{18}$.

The occurrence of respiratory distress syndrome increased the overall quality of life in the caregiver's perception, but not in the adolescent's opinion. Due to advances in intensive neonatal care, this disease is currently quite well controlled. This may explain why it was not associated with quality of life in the adolescent's opinion. However, it is difficult to explain the caregiver's opinion, since there is no known biological reason for this occurrence. It may be possible that, this disease occurring soon after birth had a significant psychological impact for the mother, representing a marker of the fragility of the baby's condition. Thus, once the baby survived this illness, the mother would be more confident 
about the child's future and would see him as able to overcome other adversities.

The need for frequent hospitalizations contributed to the reduction of the adolescent's quality of life score in the caregiver's perception. This fact clearly reflects the presence of sequelae of prematurity with diseases that require hospitalization treatment. It is known that children and adolescents born preterm have high numbers of hospitalizations after discharge from the neonatal unit, mainly due to respiratory diseases ${ }^{19,20}$.

In these situations, the mother again experiences the vicissitudes of the processes of separation and psychic pain. The mother judged that the pain/guilt because of prematurity was "resolved" when the patient was discharged from a prolonged neonatal ICU stay, and successive hospitalizations would represent new states of impotence and endless imprisonment, decreasing the child's quality of life scores.

The lack of a fixed partner can affect the emotional state of the mother, facilitating the occurrence of depression, negative feelings and financial difficulties. According to Upton et al. ${ }^{16}$, when the child presents chronic disease, or when the mother presents signs and symptoms of stress or low socioeconomic level, in general, she cites lower quality of life scores than do the children themselves ${ }^{16}$.

The occurrence of leukomalacia was associated with a lower quality of life score in the adolescent's own perception. It is known that this lesion may be associated mainly with motor disorders but is also associated with delays in cognitive and language development ${ }^{21,22}$. Motor disturbances hamper coordination, balance, fine and gross motor control and visual motor integration, which may hamper daily activities, such as dressing, tying shoes, writing and performing physical activity, compromising social interactions between peers and school activities and leading to social isolation and low self-esteem ${ }^{22-24}$. Delayed cognitive development may compromise one of the fundamental aspects for the future of children represented by learning ability and school performance. Language disorders can compromise socialization, reading, comprehension and school performance. Thus, it is clear that leukomalacia may, in fact, compromise the quality of life of the premature.

The choice of a validated and a widely used questionnaire with a high degree of reliability and that privileged the perception of quality of life, rather than an evaluation of the health conditions of the premature, met the objective of the study because the intent was to evaluate the individual's perception about their life condition in the context in which he/she is inserted ${ }^{7,25-27}$.

As a limitation of the study, we can cite the lack of a control group of full-term adolescents. Another limitation may be the small sample size, although there was no compromise in the internal validity of the questionnaire. However, this is the first Brazilian study with this sample of preterm adolescents with very low birth weight including a participation rate of $80 \%$, which is a strong point of the research.

\section{CONCLUSIONS}

In conclusion, it can be said that caregivers attributed lower quality of life scores than adolescents. In the caregivers' perception, the variables absence of fixed partner and need for hospital admissions during childhood reduced the overall score of the adolescent' quality of life and the occurrence of respiratory distress syndrome increased this score. In the adolescents' perception, periventricular leukomalacia was associated with lower score of overall quality of life. This study suggests that adolescents born prematurely can report their quality of life independently of their caregivers, and that, their perception can be negatively associated with a neurological impairment. However, one has to consider that the perception of the quality of life has an individual, subjective and multidimensional dimension, which means that different people can perceive similar clinical and social conditions in different ways.

\section{INDIVIDUAL CONTRIBUTIONS}

Rozane Casseb - Contributed to the conception and design of the study, applied the WHOQOL-Bref questionnaire, draft the manuscript and approved the final version of the manuscript.

Ethel Battikha - Contributed to the conception and design of the study, analyzed and interpreted data, critically revised and approved the final version of the manuscript.

Anna Luiza Vieira - Contributed to the conception and design of the study, collected clinical data, critically revised and approved the final version of the manuscript

Ana Lucia Goulart - Contributed to the conception and design of the study, analyzed and interpreted data, and critically revised, and approved the final version of the manuscript.

Marina Barros - Contributed to the conception and design of the study, analyzed and interpreted data, and critically revised and approved the final version of the manuscript.

Amélia dos Santos - Contributed to the conception and design of the study, supervised the study, analyzed and interpreted data, wrote the final form of the manuscript and critically revised and approved the final version of the manuscript.

\section{CONFLICTS OF INTEREST}

We have no potential conflicts of interest. 


\section{ACKNOWLEDGEMENTS}

To the WHOQOL-Information, Evidence and Research Department of the World Health Organization, Geneva, Switzerland for authorizing the use of the WHOQOL-BREF questionnaire.

To Prof. Dr. Marcelo Pio de Almeida Fleck for the support and encouragement.

\section{REFERENCES}

1. Allen MC. Neurodevelopmental outcomes of preterm infants. Curr Opin Neurol. 2008;21(2):123-8.

2. Saigal S. Quality of life of former premature infants during adolescence and beyond. Early Hum Dev. 2013;89(4):209-13.

3. Jarjour IT. Neurodevelopmental Outcome After Extreme Prematurity: A Review of the Literature. Pediatr Neurol. 2015;52(2):143-52.

4. Sousa DA, Bosa VL, Schuch I, Goldani M, Isolan LR, Teche SP, et al. Internalizing disorders and quality of life in adolescence: evidence for independent associations. Rev Bras Psiquiatr. 2014;36(4):305-12

5. Zwicker JG, Harris SR. Quality of life of formerly preterm and very low birth weight infants from preschool age to adulthood: a systematic review. Pediatrics. 2008;121(2):e366-76.

6. Saigal S, Ferro MA, Van Lieshout RJ, Schmidt LA, Morrison KM, Boyle MH. Health-related quality of life trajectories of extremely low birth weight survivors into adulthood. J Pediatr. 2016:179:68-73

7. Fleck MP, Leal OF, Louzada S, Xavier M, Chachamovich E, Vieira G, et al. Aplicação da versão em português do instrumento abreviado de avaliação da qualidade de vida "WHOQOLBREF". Rev Saude Publica. 2000;34(2):178-83.

8. Cronbach LJ. Coefficient alpha and the internal structure of the test. Psychometrika. 1951:16:297-334.

9. Hallin AL, Stjernqvist K. Adolescents born extremely preterm: behavioral outcomes and quality of life. Scand J Psychol. 2011;52(3):251-6.

10. Baumgardt M, Bucher HU, Mieth RA, Fauchère JC. Health-related quality of life of former very preterm infants in adulthood. Acta Paediatr. 2012;101(2):e59-63.

11. Roberts G, Burnett AC, Lee KJ, Cheong J, Wood SJ, Anderson PJ, et al. Quality of life at age 18 years after extremely preterm birth in the post-surfactant era. J Pediatr. 2013;163(4):100813.e1.

12. Albrecht GL, Devlieger PJ. The disability paradox: high quality of life against all odds. Soc Sci Med. 1999;48(8):977-88.
13. Parsons SK, Fairclough DL, Wang J, Hinds PS. Comparing longitudinal assessments of quality of life by patient and parent in newly diagnosed children with cancer: the value of both raters' perspectives. Qual Life Res. 2012;21:915-23.

14. Wolke D, Chernova J, Eryigit-Madzwamuse S, Samara M, Zwierzynska K, Petrou S. Self and parent perspectives on health-related quality of life of adolescents born very preterm. J Pediatr. 2013;163(4):1020-6.

15. Pontes $G A$, Cantillino A. The influence of premature birth in mother-baby relationship. J Bras Psiquiatr. 2014;63(4):290-8.

16. Upton P, Lawford J, Eiser C. Parent-child agreement across child health-related quality of life instruments: a review of the literature. Qual Life Res. 2008;17:895-913.

17. Eiser C, Varni JW. Health-related quality of life and symptom reporting: similarities and differences between children and their parents. Eur J Pediatr. 2013;172:1299-304.

18. Resch B, Mühlanger A, Maurer-Fellbaum U, Pichler-Stachl E, Resch E, Urlesberger B. Quality of Life of Children with Cystic Periventricular Leukomalacia - A Prospective Analysis with the Child Health Questionnaire-Parent Form 50. Front Pediatr. 2016;4:50.

19. Tsopanoglou SP, Davidson J, Goulart AL, de Moraes Barros MC, dos Santos AM. Functional capacity during exercise in very-low-birth-weight premature children. Pediatr Pulmonol. 2014:49(1):91-8

20. Gonçalvez C, Wandalsen G, Lanza F, Goulart AL, Solé D, dos Santos A. Repercussions of preterm birth on symptoms of asthma, allergic diseases and pulmonary function, 6-14 years later. Allergol Immunopathol (Madr). 2016;44(6):489-96.

21. Linsell L, Malouf R, Morris J, Kurinczuk JJ, Marlow N. Prognostic factors for cerebral palsy and motor impairment in children born very preterm or very low birthweight: a systematic review. Dev Med Child Neurol. 2016: 58:554-69.

22. Arberet $C$, Proisy M, Fausser JL, Curt M, Bétrémieux P, Tréguier C, et al. Isolated neonatal MRI punctate white matter lesions in very preterm neonates and quality of life at school age. J Neonatal Perinatal Med. 2017;10(3):257-66.

23. Davis AS, Hintz SR, Van Meurs KP, Li L, Das A, Stoll BJ, et al. Developmental coordination disorder at 8 years of age in a regional cohort of extremely-low birth weight or very preterm infants. Dev Med Child Neurol. 2007:49:325-330.

24. Burns YR, Danks M, O'Callaghan MJ, Gray PH, Cooper D, Poulsen L. Motor coordination difficulties and physical fitness of extremely-low-birthweight children. Dev Med Child Neurol. 2009:51:136-42

25. Medeiros TH, Caputo EL, Domingues MR. Body dissatisfaction among women attending gym clubs. J Bras Psiquiatr. 2017:66(1):38-44.

26. Alminhana L0, Menezes Jr A, Moreira-Almeida A. Personality, religiosity, and quality of life in individuals with anomalous experiences in religious groups. J Bras Psiquiatr. 2013;62(4):268-74

27. da Cunha DH, Moraes MA, Benjamin MR, dos Santos AM. Perception of quality of life and factors associated with scores of quality of life of students of a medical school. J Bras Psiquiatr. 2017;66(4):189-96. 